\title{
Opioids for Treatment of Pre-hospital Acute Pain: A Systematic Review
}

\author{
Kristian Dahl Friesgaard · Gunn Elisabeth Vist · Per Kristian Hyldmo • \\ Lasse Raatiniemi · Jouni Kurola · Robert Larsen · Poul Kongstad • \\ Vidar Magnusson · Mårten Sandberg · Marius Rehn · Leif Rognås
}

Received: October 4, 2021 / Accepted: December 10, 2021 / Published online: January 18, 2022

(C) The Author(s) 2022

\section{ABSTRACT}

Introduction: Acute pain is a frequent symptom among patients in the pre-hospital setting, and opioids are the most widely used class of drugs for the relief of pain in these patients.

Supplementary Information The online version contains supplementary material available at https:// doi.org/10.1007/s40122-021-00346-w.

K. D. Friesgaard $(\bowtie)$

Research Department, Prehospital Emergency

Medical Service, Central Denmark Region, Olof

Palmes Allé 34, 8200 Aarhus, Denmark

e-mail: k.friesgaard@me.com

K. D. Friesgaard

Department of Anaesthesiology, Regional Hospital of Horsens, Horsens, Denmark

K. D. Friesgaard · L. Rognås

Department of Anaesthesiology, Aarhus University

Hospital, Aarhus, Denmark

G. E. Vist

Division for Health Services, Norwegian Institute of Public Health, Oslo, Norway

P. K. Hyldmo · M. Rehn

Faculty of Health Sciences, University of Stavanger, Stavanger, Norway

P. K. Hyldmo · M. Rehn

Department of Research, Norwegian Air Ambulance

Foundation, Oslo, Norway
However, the evidence base for opioid use in this setting appears to be weak. The aim of this systematic review was to explore the efficacy and safety of opioid analgesics in the pre-hospital setting and to assess potential alternative therapies.

Methods: The PubMed, EMBASE, Cochrane Library, Centre for Reviews and Dissemination, Scopus, and Epistemonikos databases were searched for studies investigating adult patients

\section{P. K. Hyldmo}

Trauma Unit, Sørlandet Hospital, Kristiansand, Norway

L. Raatiniemi

Centre for Prehospital Emergency Care, Oulu

University Hospital, Oulu, Finland

L. Raatiniemi

Anaesthesia Research Group, MRC, Oulu University Hospital and University of Oulu, Oulu, Finland

J. Kurola

Centre for Prehospital Emergency Medicine, Kuopio University Hospital and University of Eastern Finland, Kuopio, Finland

R. Larsen

Department of Biomedical and Clinical Sciences (BKV), Linköping University, Linköping, Sweden

P. Kongstad

Department of Prehospital Care and Disaster Medicine, Region of Skåne, Lund, Sweden 
with acute pain prior to their arrival at hospital. Outcomes on efficacy and safety were assessed. Risk of bias for each included study was assessed according to the Cochrane approach, and confidence in the evidence was assessed using the GRADE method.

Results: A total of 3453 papers were screened, of which the full text of 125 was assessed. Twelve studies were ultimately included in this systematic review. Meta-analysis was not undertaken due to substantial clinical heterogeneity among the included studies. Several studies had high risk of bias resulting in low or very low quality of evidence for most of the outcomes. No pre-hospital studies compared opioids with placebo, and no studies assessed the risk of opioid administration for subgroups of frail patients. The competency level of the attending healthcare provider did not seem to affect the efficacy or safety of opioids in two observational studies of very low quality. Intranasal opioids had a similar effect and safety profile as intravenous opioids. Moderate quality evidence supported a similar efficacy and safety of synthetic opioid compared to morphine.

Conclusions: Available evidence for pre-hospital opioid administration to relieve acute pain is scarce and the overall quality of evidence is low. Intravenous administration of synthetic, fastacting opioids may be as effective and safe as intravenous administration of morphine. More controlled studies are needed on alternative routes for opioid administration and pre-hospital pain management for potentially more frail patient subgroups.

V. Magnusson

Landspitalinn University Hospital, Reykjavik, Iceland

M. Sandberg · M. Rehn

Division of Prehospital Services, Air Ambulance

Department, Oslo University Hospital, Oslo, Norway

L. Rognås

Department of Clinical Medicine, Aarhus

University, Aarhus, Denmark

L. Rognås

Danish Air Ambulance, Aarhus, Denmark
Keywords: Pre-hospital; Emergency medicine; Acute pain; Opioids

\section{Key Summary Points}

Opioids are frequently used as treatment for acute pain in pre-hospital patients.

Twelve studies were included in a systematic review to assess the efficacy and safety of opioids in this setting.

Several studies had high risk of bias, resulting in low or very low quality of evidence.

Studies on pre-hospital opioid administration to relieve acute pain is scarce and overall quality of evidence is low.

\section{INTRODUCTION}

Acute pain remains a common symptom in patients requiring emergency care [1-4]. Early and appropriate relief of acute pain is recommended in the pre-hospital acute phase of care to ease transportation of the patient to the hospital while assuring patient comfort and reducing detrimental effects of pain and accompanying stress $[5,6]$. For patients experiencing moderate to severe pain, opioids are widely accepted as the mainstay of analgesic therapy. A common pharmacodynamic feature of this drug class is an effective modulation of nociceptive transmission in the central nervous system [7, 8]. The more lipophilic character of newer synthetic opioid formulas compared with morphine may enable more rapid crossing of the blood-brain barrier, allowing them to reach the target organ within a few minutes [9]. This quick analgesic onset has made synthetic opioids the analgesic of choice in some pre-hospital services. However, the rapid analgesic offset of synthetic opioids demands continuous need for patient assessment and possibly repeated titration to maintain the analgesic effect, which 
is turn requires an emergency care clinician skilled in pain evaluation and analgesic dosing. All opioids carry a risk of life-threatening side effects which must be recognized and handled promptly [7, 10]. Also, opioids have a high abuse potential, which has caused an epidemic of opioid overdose in the USA and Europe. These factors have driven an intensified search for alternative analgesics $[11,12]$. Even though the treatment of acute pain is a priority in prehospital care [13-19], the evidence base guiding treatment choices appears to be weak. Therefore, the aims of this systematic literature review on effective and safe opioid analgesia are: (1) to identify potential alternatives for intravenous opioids in pre-hospital emergency care; (2) to compare synthetic opioids with morphine in terms of relieving pain; (3) to assess whether effective and safe administration of opioids is related to the competency level (cadre) of the pre-hospital healthcare provider; (4) to examine whether alternative routes of opioid administration may be as effective and safe as intravenous administration; (5) to identify groups of patients in whom pre-hospital opioid administration should be waived or carried out with extra caution.

\section{METHODS}

This systematic review was conducted according to the Cochrane Handbook for Systematic Reviews of Interventions [20]. It is part of a comprehensive literature review (PROSPERO registration number: CRD42018114399) of studies on pre-hospital analgesia, with the aim to provide the basis for a clinical guideline on the subject. The review has similar methodologies as described elsewhere [21, 22]. The task force conducting the guideline was appointed by the Scandinavian Society of Anaesthesia and Intensive care medicine (SSAI) [23].

\section{Inclusion Criteria}

The following inclusion criteria were used:

Population: Pre-hospital adult patients with acute pain
Interventions: Synthetic opioids, other analgesics, no analgesics or opioids given by a different route of administration

Comparison: Morphine administered intravenously

Outcomes: $\quad$ Pain reduction (change in pain scores); speed of onset; duration of effect; relevant adverse effects, such as nausea and vomiting; pruritus; hypotension; hypoxemia; and respiratory failure. Where investigated, serious outcomes, such as mortality and anaphylaxis, are reported

In addition to the endpoints listed in PROSPERO, our aim to assess whether effective and safe administration of opioids is related to the competency level of the pre-hospital healthcare provider. We therefore compared physicians with non-physicians. We included systematic reviews and randomized controlled trials (RCTs) of adult patients with acute pain, regardless of etiology, managed in the pre-hospital setting. Due to a limited number of studies, we also considered non-RCTs, cohorts with control group, interrupted time-series, and controlled before-after studies.

\section{Exclusion Criteria}

Studies including children and patients with chronic pain were excluded. Also excluded were studies not conducted in the pre-hospital setting (due to major concerns of indirectness), as well as conference abstracts and publications without results available in full text. Studies addressing the efficacy and safety of ketamine compared with opioids were explored in a previously published review conducted by the same task force [22]. Studies on inhaled analgesia (for example, methoxyflurane) will be reported in another review by the same task force. 


\section{Search Strategy}

A medical research librarian developed the search strategy in collaboration with the authors. The following databases were searched from their inception: PubMed, EMBASE, Cochrane Library, Centre for Reviews and Dissemination, Scopus, and Epistemonikos. The most recent update of the search was conducted 4 January 2021. The complete search strategies are presented in Electronic Supplementary Material Appendix 1. Because few available studies were expected, we designed a broad search strategy so as not to miss any relevant studies-hence the relatively large number of references identified by the searches. The search was limited to articles published in English, Danish, Norwegian, and Swedish.

\section{Study Selection}

No assessor reviewed a study that they had (co)authored. Three authors (LR and either KDF or $\mathrm{PKH}$ ) independently assessed all titles and abstracts identified from the search according to the inclusion criteria, as described in our previous reviews [21, 22]. References considered to be potentially relevant were collected and assessed independently in full text by two assessors using the same inclusion criteria $[21,22]$. Disagreements were resolved by discussion among all three assessors. Study selection was based on title and abstract. The full text and risk of bias was assessed using the Covidence online systematic review collaboration platform (Veritas Health Innovation, Melbourne, Australia) [24].

\section{Assessment of Risk of Bias}

In accordance with the Cochrane Handbook for Systematic Reviews of Interventions [20], the following items were assessed: (1) sequence generation; (2) concealment of allocation; (3) blinding of participants and personnel; (4) blinding of outcome assessor; (5) incomplete outcome data; (6) selective outcome reporting; and (7) other risk of bias. For non-RCTs and other studies with a control group, the following items were also assessed: (8) similarity of baseline characteristics; (9) similarity of baseline outcome data; and (10) free of contamination. All items were rated as high, unclear, or low risk of bias.

\section{Data Extraction and Analysis}

As described elsewhere [21, 22], we extracted data pertaining to full reference; study design and country in which the study was conducted; characteristics of the population (e.g., number of patients, age, gender, cause of pain, setting, and context); type and dose of analgesics given; competency of the healthcare personnel who administered the analgesic; comparison/control intervention; attrition; outcomes; and followup times.

Dichotomous outcomes are presented as the risk ratio (RR) with associated 95\% confidence interval (CI). Continuous outcomes are presented as the mean difference between the groups (MD) with associated 95\% CI. Where different scales were used to measure the same outcome, we calculated the standardized mean difference (SMD) with 95\% CI. We used Review Manager version 5.3 (The Nordic Cochrane Centre, Copenhagen, Denmark) to generate forest plots. Due to substantial clinical heterogeneity between the included studies, metaanalyses were not undertaken. Several of the included studies reported results for each group without making a comparison between them; in these cases, we made these calculations using Review Manager version 5.3 to find the SMD (95\% CI).

\section{Grading our Confidence in the Evidence}

Using the Grading of Recommendations Assessment, Development and Evaluation (GRADE) approach, we graded our confidence in the evidence for each outcome and presented results as high, moderate, low, or very low quality [25]. The evidence across each outcome 


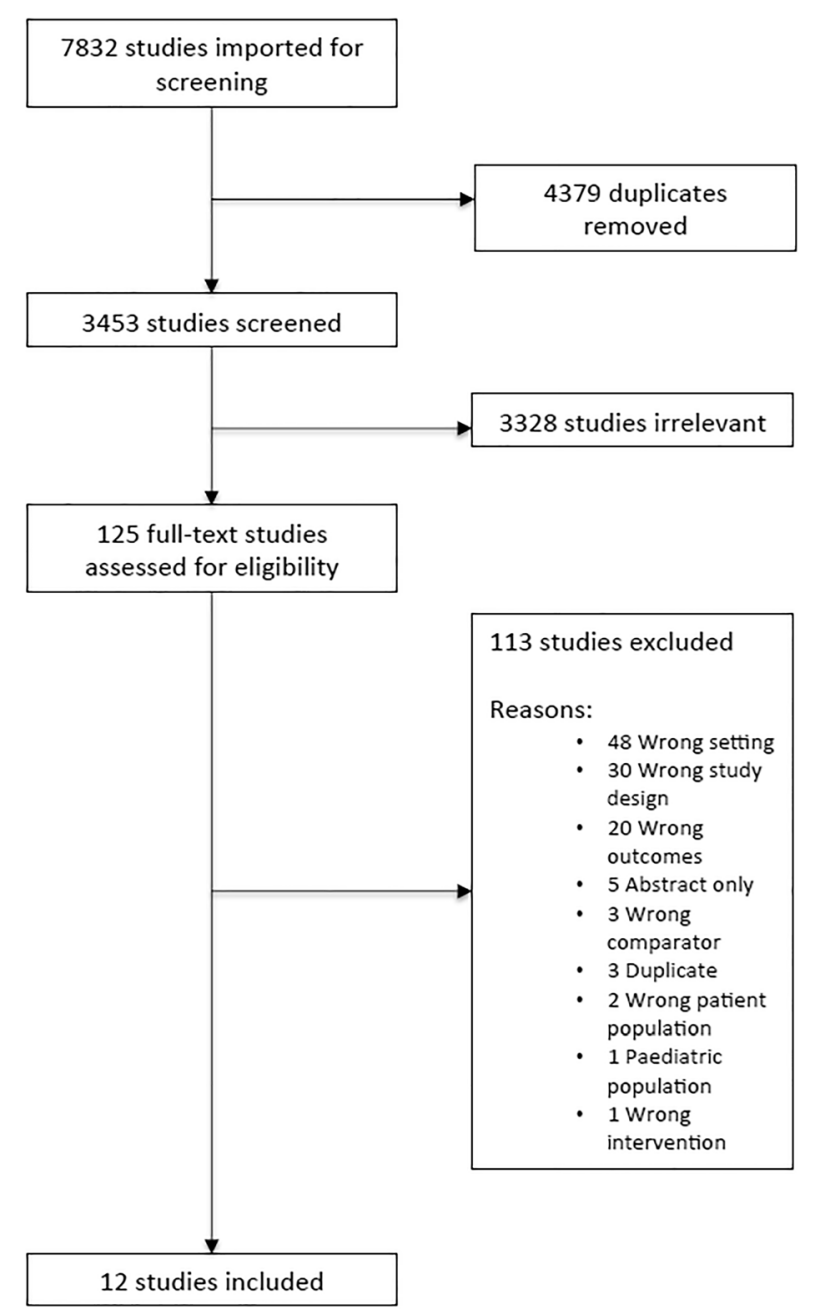

Fig. 1 PRISMA (Preferred Reporting Items for Systematic Reviews and Meta-Analyses) flow diagram of study selection

was assessed by eight criteria: five criteria could lower our confidence in the evidence, and three criteria could be used to consider upgrading evidence from observational studies that had not been downgraded [25]. According to GRADE, when the effect of interventions is assessed, RCTs start at high, and observational studies start at low [25].

\section{Compliance with Ethics Guidelines}

This article is based on previously conducted studies and does not contain any new studies with human participants or animals performed by any of the authors.

\section{RESULTS}

The literature search identified 3453 papers, of which 125 were assessed in full text. Ultimately, 12 studies were included in this systematic review. A PRISMA flow diagram of study selection is given in Fig. 1 . Table 1 provides a summary of the studies included in this review. 
Table 1 Summary of included studies

\begin{tabular}{|c|c|c|c|}
\hline $\begin{array}{l}\text { Reference/Study } \\
\text { design/Country }\end{array}$ & Intervention & Comparison & Outcomes \\
\hline \multicolumn{4}{|c|}{ Opioids versus placebo or no analgesic treatment } \\
\hline $\begin{array}{l}\text { Puymirat et al. } \\
\text { [29]/ } \\
\text { Retrospective } \\
\text { cohort study/ } \\
\text { France }\end{array}$ & $\begin{array}{l}n=453, \text { morphine administration form or } \\
\text { dose not described }\end{array}$ & $\begin{array}{l}n=1985, \text { no morphine administered } \\
\text { in the prehospital setting }\end{array}$ & In-hospital death, 1-year survival \\
\hline \multicolumn{4}{|c|}{ Morphine versus synthetic opioids } \\
\hline $\begin{array}{l}\text { Galinski et al. } \\
\text { [32]/RCT/ } \\
\text { France }\end{array}$ & $\begin{array}{l}n=28, \text { i.v. fentanyl dose of } 1 \mu \mathrm{g} / \mathrm{kg} \text { followed } \\
\text { by additional doses of } 30 \mu \mathrm{g} \text { until pain relief }\end{array}$ & $\begin{array}{l}n=26 \text {, i.v. morphine dose of } 0.1 \mathrm{mg} / \\
\mathrm{kg} \text { followed by additional doses of } \\
3 \mathrm{mg} \text { until pain relief }\end{array}$ & $\begin{array}{l}\text { Effect: Change in VAS }(0-10) \text { from } \\
\text { baseline to } 30 \text { min after drug } \\
\text { administration } \\
\text { Safety: Comparison af various vital signs } \\
\text { and side effects (nausea, dizziness, } \\
\text { dysphoria, emesis, pruritus) }\end{array}$ \\
\hline $\begin{array}{l}\text { Bounes et al. } \\
{[28] / \text { RCT/ }} \\
\text { France }\end{array}$ & $\begin{array}{l}n=54 \text {, i.v. sufentanil dose of } 0.15 \mu \mathrm{g} / \mathrm{kg} \\
\text { followed by additional doses of } 0.075 \mu \mathrm{g} / \mathrm{kg} \\
\text { every } 3 \text { min until pain relief }\end{array}$ & $\begin{array}{l}n=54, \text { i.v. morphine dose of } 0.15 \mathrm{mg} / \\
\mathrm{kg} \text { followed by additional doses of } \\
0.075 \mathrm{mg} / \mathrm{kg} \text { every } 3 \mathrm{~min} \text { until pain } \\
\text { relief }\end{array}$ & $\begin{array}{l}\text { Effect: Change in NRS }(0-10) \text { from } \\
\text { baseline to } 30 \text { min after drug } \\
\text { administration } \\
\text { Safety: Comparison af various vital signs } \\
\text { and side effects (nausea, emesis, } \\
\text { dizziness and pruritus) }\end{array}$ \\
\hline $\begin{array}{l}\text { Smith et al. [26]/ } \\
\text { qRCT/USA }\end{array}$ & $\begin{array}{l}n=100 \text {, i.v. fentanyl dose of } 50 \mu \mathrm{g} \text { followed } \\
\text { by additional four doses (maximum } 250 \mu \mathrm{g} \text { ) } \\
\text { until pain relief }\end{array}$ & $\begin{array}{l}n=104, \text { i.v. morphine dose of } 4 \mathrm{mg} \\
\text { followed by additional four doses } \\
\quad \text { (maximum } 20 \mathrm{mg} \text { ) until pain relief }\end{array}$ & $\begin{array}{l}\text { Effect: Change in NRS }(0-10) \text { from } \\
\text { baseline to registration of final pain } \\
\text { score } \\
\text { Safety: Incidence of hypoxia } \\
\quad\left(\mathrm{SpO}_{2}<95 \%\right) \text {, hypotension } \\
\quad(\mathrm{SBP}<100 \mathrm{mmHg}) \text {, pruritus and } \\
\text { nausea or vomiting }\end{array}$ \\
\hline $\begin{array}{l}\text { Weldon et al. } \\
\text { [30]/RCT/ } \\
\text { Canada }\end{array}$ & 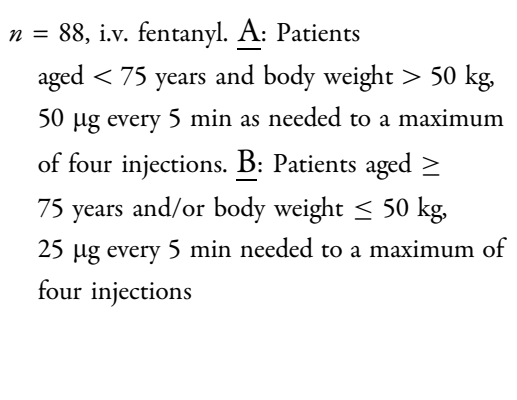 & $\begin{array}{l}n=99, \text { i.v. morphine. } \underline{\text { A: Patients }} \\
\text { aged }<75 \text { years and body weight } \\
>50 \mathrm{~kg}, 5 \mathrm{mg} \text { every } 5 \mathrm{~min} \text { as } \\
\text { needed to a maximum of four } \\
\text { injections. B } \text { : Patients } \\
\text { aged } \geq 75 \text { years and/or body } \\
\text { weight } \leq 50 \mathrm{~kg}, 2.5 \mathrm{mg} \text { every } 5 \mathrm{~min} \\
\text { needed to a maximum of four } \\
\text { injections }\end{array}$ & $\begin{array}{l}\text { Effect: Change in VAS }(0-10) \text { and } \\
\text { NRS }(0-10) \text { from baseline to } 30 \mathrm{~min} \\
\text { after drug administration } \\
\text { Safety: Comparison af various vital signs } \\
\text { and side effects (nausea, emesis and } \\
\text { apnoea). Incidence of hypotension } \\
\text { (SBP }<90 \mathrm{mmHg} \text { ) }\end{array}$ \\
\hline $\begin{array}{l}\text { Vergnion et al. } \\
\text { [27]/RCT/ } \\
\text { Belgium }\end{array}$ & $\begin{array}{l}n=53 \text {, i.v. tramadol. Initial dose } 100 \mathrm{mg} \text {, } \\
\text { followed by a further dose of } 50 \mathrm{mg} \text { every } \\
5 \mathrm{~min} \text { to a maximum of } 200 \mathrm{mg}\end{array}$ & $\begin{array}{l}n=48 \text {, i.v. morphine. A: Patients with } \\
\text { body weight }<71 \mathrm{~kg} \text { : Initial dose } \\
5 \mathrm{mg} \text {, followed by a further dose of } \\
5 \mathrm{mg} \text { every } 5 \mathrm{~min} \text { to a maximum of } \\
15 \mathrm{mg} \text {. B: Patients with body } \\
\text { weight }>70 \mathrm{~kg} \text { : Initial dose } 10 \mathrm{mg}, \\
\text { followed by a further dose of } 5 \mathrm{mg} \\
\text { every } 5 \mathrm{~min} \text { to a maximum of } 20 \mathrm{mg}\end{array}$ & $\begin{array}{l}\text { Effect: Change in VRS ( } 0-3) \text { from } \\
\text { baseline to } 40 \text { min after drug } \\
\text { administration } \\
\text { Safety: Difference in sedation score and } \\
\text { comparison of side effects (nausea and } \\
\text { vomiting) }\end{array}$ \\
\hline
\end{tabular}


Table 1 continued

\begin{tabular}{lll}
\hline $\begin{array}{l}\text { Reference/Study } \\
\text { design/Country }\end{array}$ & Intervention & Comparison \\
\hline $\begin{array}{l}\text { Silfvast et al. } \\
{[31] / \mathrm{RCT} /}\end{array}$ & $n=16$, i.v. alfentanil. Initial dose $0.5 \mathrm{mg}$, & $n=20$, i.v. morphine. Initial dose \\
Finland & $\begin{array}{l}\text { followed by a further dose of } 0.5 \mathrm{mg} \text { to a } \\
\text { maximum of } 1 \mathrm{mg}\end{array}$ & $\begin{array}{c}5 \mathrm{mg} \text {, followed by a further dose of } \\
5 \mathrm{mg} \text { to a maximum of } 10 \mathrm{mg}\end{array}$
\end{tabular}

Outcomes

Fleischman et al. $\quad n=363$, i.v. fentanyl. Initial dose $50 \mu \mathrm{g}$,

$[35] /$ followed by further doses of 25-50 $\mu \mathrm{g}$ every

Observational

before-after

study/USA $n=355$, i.v. morphine. Initial dose

$2-5 \mathrm{mg}$, followed by further doses of

2-5 $\mathrm{mg}$ every $5 \mathrm{~min}$ to a maximum of $20 \mathrm{mg}$

Effect: Difference in VAS (0-50) from baseline to $15 \mathrm{~min}$ after drug administration

Safety: Comparison af various vital signs and side effects (nausea, dizziness and fatigue)

Effect: Change in NRS (0-10) from baseline to registration of final pain score

Safety: Comparison af various vital signs and side effects (nausea and vomiting). Incidence of hypoxia $\left(\mathrm{SpO}_{2}<92 \%\right.$ and $5 \%$ below baseline)

High competency level versus lower competency level

$\begin{array}{ll}\text { Lennssen et al. } & n=149, \text { paramedics supported by EMS } \\ {[36] /} & \text { physicians to administer morphine using a } \\ \text { Retrospective } & \text { standard operating procedure } \\ \text { cohort study/ } & \\ \text { Germany } & \end{array}$

Brokmann et al.

[37]/

Retrospective

cohort study/

Germany

Intravenous opioids versus intranasal opioids

Rickard et al.

[33]/RCT/

Australia $n=80$, paramedics supported by EMS physicians to administer morphine using a standard operating procedure $n=199$, pain treatment left to the discretion of the treating on-scene physician

$n=80$, pain treatment left to the discretion of the treating on-scene physician
Effect: Change in NRS (0-10) from baseline to end of mission

Safety: Comparison af various vital signs and side effects (nausea and vomiting) or signs of respiratory- or circulatory insufficiency

Effect: Change in NRS (0-10) from baseline to end of mission

Safety: Comparison af various vital signs and side effects (nausea and vomiting)

Effect: Change in NRS (0-10) from baseline to destination

Safety: Comparison af various vital signs and side effects (low respiratory rate, hypotension, dizziness, nausea, bad taste, itching, watery eyes, nasal congestion, irritated throat, chest tightness, dysphoria/depression) 
Table 1 continued

\begin{tabular}{lccc}
\hline $\begin{array}{l}\text { Reference/Study } \\
\text { design/Country }\end{array}$ & Intervention & Comparison & Outcomes \\
\hline $\begin{array}{l}\text { Middleton et al. } \\
{[34] /}\end{array}$ & $n=3778$, i.n. fentanyl. Initial dose of $240 \mu \mathrm{gg}$ & $n=12,955$, i.v. morphine. Initial dose \\
with subsequent doses of $60-120 \mu \mathrm{g}$ every & offect: Change in NRS (0-10) from \\
every $2 \mathrm{~min}$ until pain relief to a & & baseline to final pain score recording \\
cohort study/ & 5 min as required, no maximum dose & maximum of $0.5 \mathrm{mg} / \mathrm{kg}$ & \\
Australia & & & \\
\hline
\end{tabular}

CI Confidence interval, EMS Emergency Medical Service, i.v. intravenous, i.n. intranasal, $n$ number, $v$ sersus, $N R S$ numeric rating scale, $q R C T$ quasiexperimental RCT, $R C T$ randomized controlled trial, $S B P$ systolic blood pressure, $S_{p} O_{2}$ oxygen saturation, $V A S$ visual analogue scale, VRS verbal rating scale

\section{Characterization of the Trials}

The 12 included studies were conducted in France (3), Australia (2), the USA (2), Germany (2), Canada (1), Belgium (1), and Finland (1) and included trauma patients [26-28], patients with chest pain [29-31], and patients with acute pain arising from various etiologies [32-37]. A total of 21,317 pre-hospital patients with acute pain were included: 917 patients in seven RCTs, 2601 patients in a controlled cohort study, 718 patients in a controlled before-after study, and 17,081 patients in three observational studies. Although one study included both adults and adolescents, the vast majority of patients were adults, as indicated by the median (95\% CI) age, which was 59 (56-61) years in one group and 61 (59-63) years in the other group [35].

Various pain scales and outcomes were used in the 11 studies measuring efficacy, with seven studies reporting pain intensity on a verbal Numeric Rating Scale (NRS, 0-10) $[27,28,33-37]$, three studies using the Visual Analogue Scale (VAS 0-100 [30, 32] or VAS 0-50 [31]), and one study reporting pain on a 4-point Verbal Rating Scale (VRS-4) [27]. Pain outcomes were reported as change in pain scores in ten studies [26, 27, 30-37] and pain relief (NRS < 4) 15 min after study drug administration in one study [28]. Seven studies used an unspecified observation period from baseline to hospital arrival [26, 27, 33-37], whereas four studies used fixed time-points of $15 \mathrm{~min}[28,30,31]$ or $30 \mathrm{~min}$ [32].
The studies were heterogenic in terms of safety reporting, with a widespread recording of various adverse effects: nausea $[28,30-32$, 35-37], emesis [27, 28, 30, 32, 33], nausea and vomiting [27], fatigue [31], sedation (reduction in Glasgow Coma Scale or sedation score) $[27,28,32,35]$, dizziness $[27,28,31-33]$, dysphoria [32, 33], confusion [28], headache [28], urticaria [28], and pruritus [27, 28, 32, 33]. Hypotension was defined differently by systolic blood pressure levels in three studies $[27,30,33]$, and hypoxia or respiratory depression was defined by different cutoff values of peripheral oxygen saturation $\left(\mathrm{SpO}_{2}\right)$ in five studies [26, 28, 30, 33, 35]. Most studies combined the rare events of adverse effects to one pooled estimate.

\section{Risk of Bias Assessment}

Some trials had high risk of bias, with the main reasons being lack of random sequence generation, lack of allocation concealment, and lack of blinding of patients, personnel, and/or outcome assessor (Fig. 2).

\section{Comparisons}

The included studies covered four comparisons involving opioids (Table 2):

- Opioids [29] versus no analgesia or alternative drugs 


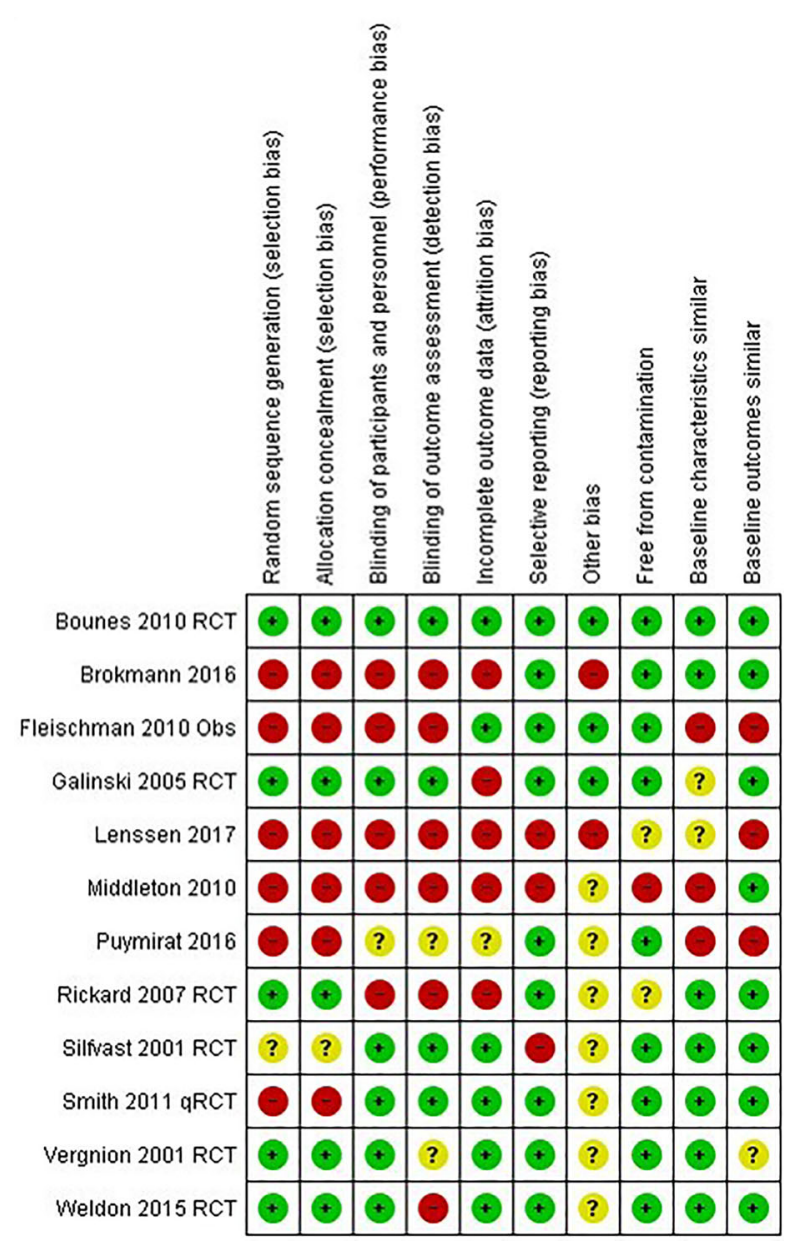

Fig. 2 Risk of bias table. Obs Observational study, $q R C T$ quasi-RCT, $R C T$ randomized controlled trial

- Morphine (intravenous [i.v.]) versus synthetic opioids (i.v. fentanyl [26, 30, 32, 35], alfentanil [31], sufentanil [28], tramadol [27])

- Physicians versus non-physicians [36, 37]

- Opioids (i.v.) versus opioids given by another route of administration (intranasal fentanyl $[33,34])$.

\section{Analysis and Grading}

Meta-analysis was not considered appropriate due to clinical heterogeneity; the studies differed substantially in terms of patient populations, interventions, comparisons, and outcomes.

Our confidence in the evidence was downgraded for various reasons (high risk of bias, inconsistency, indirectness, imprecision, and publication bias) as explained in the footnotes in Table 2. Below is a resume of the included studies for each of the comparisons.

\section{Opioids Versus No Analgesia or Alternative Drugs}

No pre-hospital studies comparing opioids with placebo, paracetamol, or non-steroidal-inflammatory drugs (NSAIDs) were identified. One pre-hospital register-based study involving 2438 patients with myocardial infarction assessed the risk related to receiving morphine for acute chest pain [29]. The study reported few events and uncertain in-hospital mortality (adjusted odds ratio [OR] $0.48,95 \%$ CI 0.12-1.85), stroke (adjusted OR 0.49, 95\% CI 0.06-4.46), stent thrombosis, bleeding or blood transfusion requirements compared with those who did not receive pre-hospital morphine (Table 2). In contrast to our review questions which considered morphine to be standard care, this study analyzed morphine as the intervention [29]. The comparison is equally relevant and was included.

Morphine (i.v.) Versus Synthetic Opioids (i.v.) Synthetic opioids were compared with i.v. morphine in seven studies (Table 2; Figs. 3, 4). We did not combine these studies in metaanalysis due to clinical heterogeneity. Change in pain score for morphine versus intranasal fentanyl showed statistical heterogeneity $\left(I^{2}=71 \%\right)$, but morphine versus i.v. fentanyl did not $\left(I^{2}=0 \%\right)$. Adverse events showed statistical heterogeneity $\left(I^{2}=61 \%\right)$. Overall, moderate quality of evidence found similar results from using synthetic opioid and morphine in terms of analgesic effect. Low quality of evidence supports that synthetic opioids and morphine are similar in the proportion of reported adverse events.

In a small RCT $(n=54)$ on both trauma and non-trauma patients, Galinski et al. compared i.v. morphine with i.v. fentanyl and found no 
Table 2 GRADE summary of findings tables for the comparisons in the systematic review

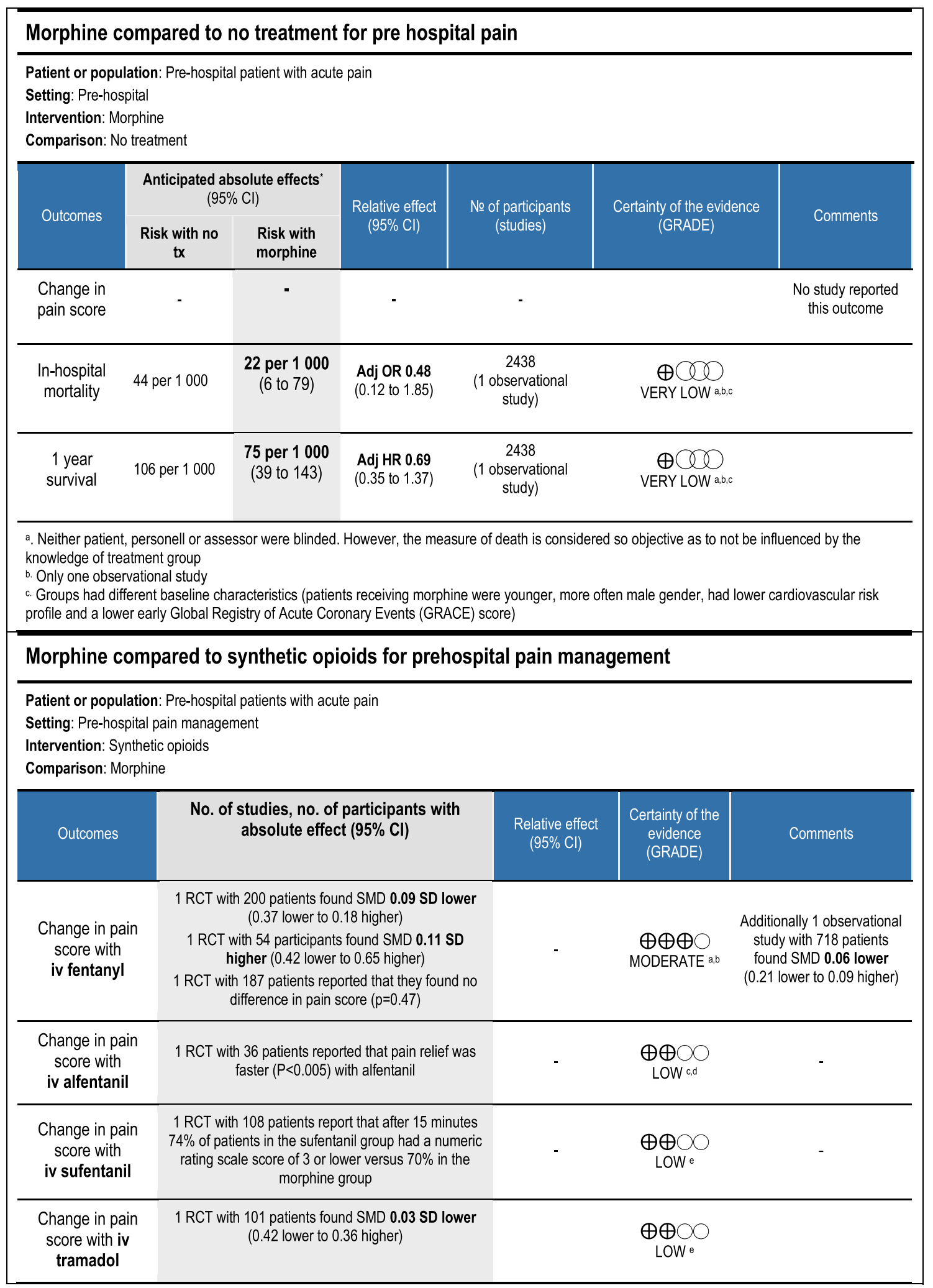




\begin{tabular}{|c|c|c|c|c|}
\hline $\begin{array}{l}\text { Adverse events } \\
\text { with iv fentanyl }\end{array}$ & $\begin{array}{c}1 \text { RCT with } 200 \text { patients found } 29 \text { more adverse } \\
\text { events per } 1000 \text { with morphine (164 fewer to } \\
414 \text { more) } \\
1 \text { RCT with } 54 \text { participants did not reports adverse } \\
\text { events } \\
1 \text { RCT with } 187 \text { patients found } 127 \text { more adverse } \\
\text { events per } 1000 \text { with morphine (4 fewer to } 341 \text { more) }\end{array}$ & $\begin{array}{c}\text { RR } 1.08 \\
\text { (0.54 to } 2.16) \\
- \\
\text { RR } 1.59 \\
\text { (0.98 to } 2.58)\end{array}$ & $\bigoplus \bigoplus_{\text {LOW } a, b} \bigcirc$ & $\begin{array}{c}\text { Additionally } 1 \text { observational } \\
\text { study with } 718 \text { patients } \\
\text { found } 32 \text { more adverse } \\
\text { events per } 1000 \text { with } \\
\text { morphine ( } 6 \text { fewer to } 96 \\
\text { more) }\end{array}$ \\
\hline $\begin{array}{l}\text { Adverse events } \\
\text { with iv alfentanil }\end{array}$ & $\begin{array}{l}1 \text { RCT with } 36 \text { patients found } 263 \text { fewer adverse } \\
\text { events per } 1000 \text { with morphine ( } 306 \text { fewer to } 75 \text { more) }\end{array}$ & $\begin{array}{c}\text { RR } 0.16 \\
(0.02 \text { to } 1.24)\end{array}$ & $\underset{\text { LOW } \mathrm{c}, \mathrm{d}}{\bigoplus}$ & \\
\hline $\begin{array}{l}\text { Adverse events } \\
\text { with iv sufentanil }\end{array}$ & $\begin{array}{l}1 \text { RCT with } 108 \text { patients found } 0 \text { fewer adverse events } \\
\text { per } 1000 \text { with morphine (102 fewer to } 224 \text { more) }\end{array}$ & $\begin{array}{l}\text { RR } 1.00 \\
\text { (0.45 to } 2.21)\end{array}$ & $\underset{\text { LOW }}{\bigoplus \bigoplus O}$ & \\
\hline $\begin{array}{l}\text { Adverse events } \\
\text { with iv tramadol }\end{array}$ & $\begin{array}{c}1 \text { RCT with } 101 \text { patients found } 24 \text { fewer adverse } \\
\text { events per } 1000 \text { with morphine (110 fewer to } 192 \\
\text { more) }\end{array}$ & $\begin{array}{l}\text { RR } 0.86 \\
\text { (0.35 to } 2.13)\end{array}$ & $\underset{\text { LOW e }}{\bigoplus \bigoplus \bigcirc \bigcirc}$ & \\
\hline
\end{tabular}

a. Incomplete outcome reporting, lack of allocation concealment and blinding of outcome assessment

b. Very few participants in each study. However three different RCTs and one observational study reports on the same comparison and with similar

results so we downgrade with just one level

c. Unclear random generation and allocation

d. Very few participants

e. Very few participants

\section{Lower compared to higher level of competency for administrating prehospital pain management}

Patient or population: Prehospital patient with acute pain

Setting: Prehospital pain management

Intervention: Lower level of competency

Comparison: High level of competency

\begin{tabular}{|c|c|c|c|c|c|c|}
\hline \multirow[b]{2}{*}{ Outcomes } & \multicolumn{3}{|c|}{ Anticipated absolute effects" $(95 \% \mathrm{Cl})$} & \multirow{2}{*}{$\begin{array}{l}\text { Relative } \\
\text { effect } \\
(95 \% \mathrm{Cl})\end{array}$} & \multirow{2}{*}{$\begin{array}{l}\text { Certainty of } \\
\text { the evidence } \\
\text { (GRADE) }\end{array}$} & \multirow[b]{2}{*}{ Comments } \\
\hline & $\begin{array}{l}\text { Risk with high } \\
\text { level }\end{array}$ & \multicolumn{2}{|c|}{ Risk with lower level of competency } & & & \\
\hline $\begin{array}{l}\text { Change in pain } \\
\text { score }\end{array}$ & \multicolumn{3}{|c|}{$\begin{array}{l}1 \text { observational study with } 160 \text { patients report non- } \\
\text { significant reduced pain score with physician MD }-0.60 \text { (- } \\
\qquad 1.25 \text { to } 0.05) \\
\text { One observational study with } 348 \text { patients report a MD } 0.10 \\
\text { (-0.41 to } 0.61)\end{array}$} & & $\begin{array}{l}\bigoplus \bigcirc \bigcirc \bigcirc \\
\text { VERY LOW a,b }\end{array}$ & - \\
\hline Adverse events & \multicolumn{3}{|c|}{$\begin{array}{l}2 \text { observational studies with a total of } 508 \text { patients did not } \\
\text { report any adverse events }\end{array}$} & \multicolumn{2}{|r|}{$\begin{array}{l}\bigoplus \bigcirc \bigcirc \bigcirc \\
\text { VERY LOW a,b }\end{array}$} & - \\
\hline \multicolumn{7}{|c|}{$\begin{array}{l}\text { a. High risk of bias due to lack of random sequence generation, allocation concealment, blinding and incomplete outcome data and the larger of } \\
\text { the studies did not have similar outcome measures at baseline. } \\
\text { b. } \quad \text { Few events and wide confidence intervals }\end{array}$} \\
\hline \multicolumn{7}{|c|}{ Intravenous opioids compared to intranasal opioids for prehospital pain management } \\
\hline \multicolumn{7}{|c|}{$\begin{array}{l}\text { Patient or population: Prehospital patients with acute pain } \\
\text { Setting: Prehospital pain management } \\
\text { Intervention: Intranasal opioids } \\
\text { Comparison: Intravenous opioids }\end{array}$} \\
\hline \multirow[b]{2}{*}{ Outcomes } & \multicolumn{2}{|c|}{$\begin{array}{l}\text { Anticipated absolute effects }{ }^{*}(95 \% \\
\qquad \mathrm{Cl})\end{array}$} & \multirow{2}{*}{$\begin{array}{l}\text { Relative } \\
\text { effect } \\
(95 \% \mathrm{Cl})\end{array}$} & \multirow{2}{*}{$\begin{array}{l}\text { № of } \\
\text { participants } \\
\text { (studies) }\end{array}$} & \multirow{2}{*}{$\begin{array}{l}\text { Certainty } \\
\text { of the } \\
\text { evidence } \\
\text { (GRADE) }\end{array}$} & \multirow[b]{2}{*}{ Comments } \\
\hline & $\begin{array}{c}\text { Risk with } \\
\text { intranasal } \\
\text { opioids }\end{array}$ & $\begin{array}{l}\text { Risk with } \\
\text { intravenous } \\
\text { opioids }\end{array}$ & & & & \\
\hline
\end{tabular}


Table 2 continued

\begin{tabular}{|c|c|c|c|c|c|c|}
\hline $\begin{array}{l}\text { Change in pain } \\
\text { score }\end{array}$ & - & $\begin{array}{l}\text { The change in pain } \\
\text { score with } \\
\text { intravenous } \\
\text { administration was } \\
\text { SDM } 0.25 \text { SD lower } \\
\text { (0.51 lower to } 0.01 \\
\text { higher) }\end{array}$ & - & $\begin{array}{c}227 \\
(1 \mathrm{RCT})\end{array}$ & $\begin{array}{l}\oplus \oplus \bigcirc \\
L O W a, b\end{array}$ & $\begin{array}{c}1 \text { observational study } \\
\text { with } 16733 \text { patients } \\
\text { reported a SMD of } 0.0 \\
\text { SD (0.04 lower to } 0.04 \\
\text { higher) }\end{array}$ \\
\hline $\begin{array}{l}\text { Serious adverse } \\
\text { events }\end{array}$ & 150 per 1000 & $\begin{array}{c}79 \text { fewer per } 1000 \\
\text { with intravenous } \\
\text { (120 fewer to } 10 \\
\text { more) }\end{array}$ & $\begin{array}{l}\text { RR } 0.47 \\
(0.20 \text { to } \\
1.07)\end{array}$ & $\begin{array}{c}227 \\
(1 \mathrm{RCT})\end{array}$ & $\begin{array}{l}\oplus \oplus \bigcirc \\
L O W a, b\end{array}$ & \\
\hline Adverse events & 283 per 1000 & $\begin{array}{c}133 \text { fewer per } 1000 \\
\text { with intravenous } \\
\text { (196 fewer to } 26 \\
\text { fewer) }\end{array}$ & $\begin{array}{c}\text { RR } 0.53 \\
(0.31 \text { to } \\
0.91)\end{array}$ & $\begin{array}{c}227 \\
(1 \mathrm{RCT})\end{array}$ & $\begin{array}{l}\oplus \oplus \bigcirc \\
L O W a, b\end{array}$ & \\
\hline \multicolumn{7}{|c|}{$\begin{array}{l}\text { *The risk in the intervention group (and its } 95 \% \text { confidence interval) is based on the assumed risk in the comparison group and the relative } \\
\text { effect of the intervention (and its } 95 \% \mathrm{CI} \text { ). Cl: Confidence interval; SMD: Standardised mean difference }\end{array}$} \\
\hline \multicolumn{7}{|c|}{$\begin{array}{l}\text { GRADE Working Group grades of evidence } \\
\text { High certainty: We are very confident that the true effect lies close to that of the estimate of the effect } \\
\text { Moderate certainty: We are moderately confident in the effect estimate: The true effect is likely to be close to the estimate of the effect, but } \\
\text { there is a possibility that it is substantially different } \\
\text { Low certainty: Our confidence in the effect estimate is limited: The true effect may be substantially different from the estimate of the effect } \\
\text { Very low certainty: We have very little confidence in the effect estimate: The true effect is likely to be substantially different from the estimate of } \\
\text { effect }\end{array}$} \\
\hline $\begin{array}{ll}\text { a. } & \text { High ris } \\
\text { b. } & \text { Imprecis }\end{array}$ & $\begin{array}{l}\text { due to lack } \\
\text { to few event }\end{array}$ & ing, incomplete ou & la & ty & bias, & \\
\hline
\end{tabular}

difference in the change in pain scores (SMD $0.11,95 \% \mathrm{CI}-0.42$ to 0.65 , VAS $0-100$ ) or vital signs, but did observe uncertainty regarding adverse effects (RR 1.08, 95\% CI 0.54-2.16), nausea, emesis, dysphoria, pruritus, dizziness, and sedation) [32].

In a physician-staffed helicopter emergency medical service $(n=200)$, no difference was found in analgesic effect (change in mean pain scores: SMD $-0.09,95 \% \mathrm{CI}-0.37$ to 0.18 , NRS $0-10)$, occurrence of hypoxia $\left(\mathrm{SpO}_{2}<95 \%\right)$, hypotension (systolic blood pressure $<100 \mathrm{mmHg}$ ) or adverse effects (no events of pruritus or nausea or vomiting) when comparing i.v. morphine to i.v. fentanyl [26].

Weldon et al. found no difference in analgesic effect (difference in pain scores [NRS] every $5 \mathrm{~min}$ until $30 \mathrm{~min}, P=0.47$ ) of i.v. fentanyl compared with i.v. morphine in patients with chest pain $(n=207)$. The researchers also found similar vital signs and similar adverse effects (RR 1.59, 95\% CI 0.98-2.58), including nausea $(12.5 \%[n=11]$ vs. $18.2 \% \quad[n=18]$, $P=0.32)$, apnea (none), emesis $(1.1 \%[n=1)]$ vs. $2.0 \%[n=2], P=1.0)$, and antihistamine given $(8.0 \%[n=7]$ vs. $9.1 \%[n=9], P=0.8)$ [30].

A small Finnish study with 36 patients found faster and more effective immediate pain reduction when using i.v. alfentanil compared with i.v. morphine. However, at the end of the observation period only two of 20 patients $(10 \%)$ in the morphine group expressed recurring pain compared with four of $16(25 \%)$ in the alfentanil group. A non-significant trend of more adverse effects (dizziness, fatigue, and nausea: $n=5$ ([1\%] vs. $n=1 \quad[5 \%]$ ) in the alfentanil group was observed. The study also found similar vital signs in both groups [31]. 


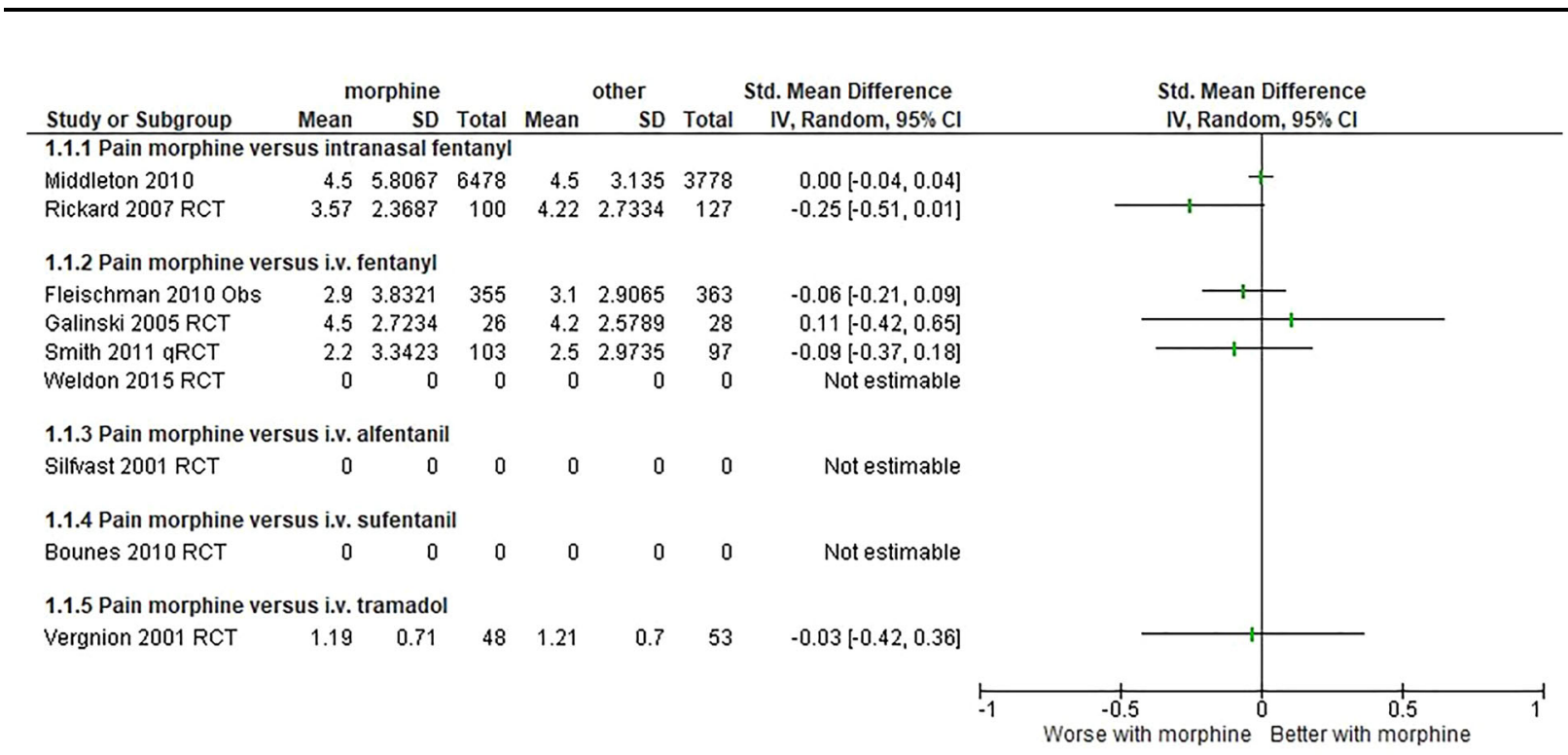

Fig. 3 Forest plot illustrating change in pain scores for patients treated with synthetic opioids vs. morphine. $C I$ Confidence interval, i.v. intravenous, $S D$ standard deviation

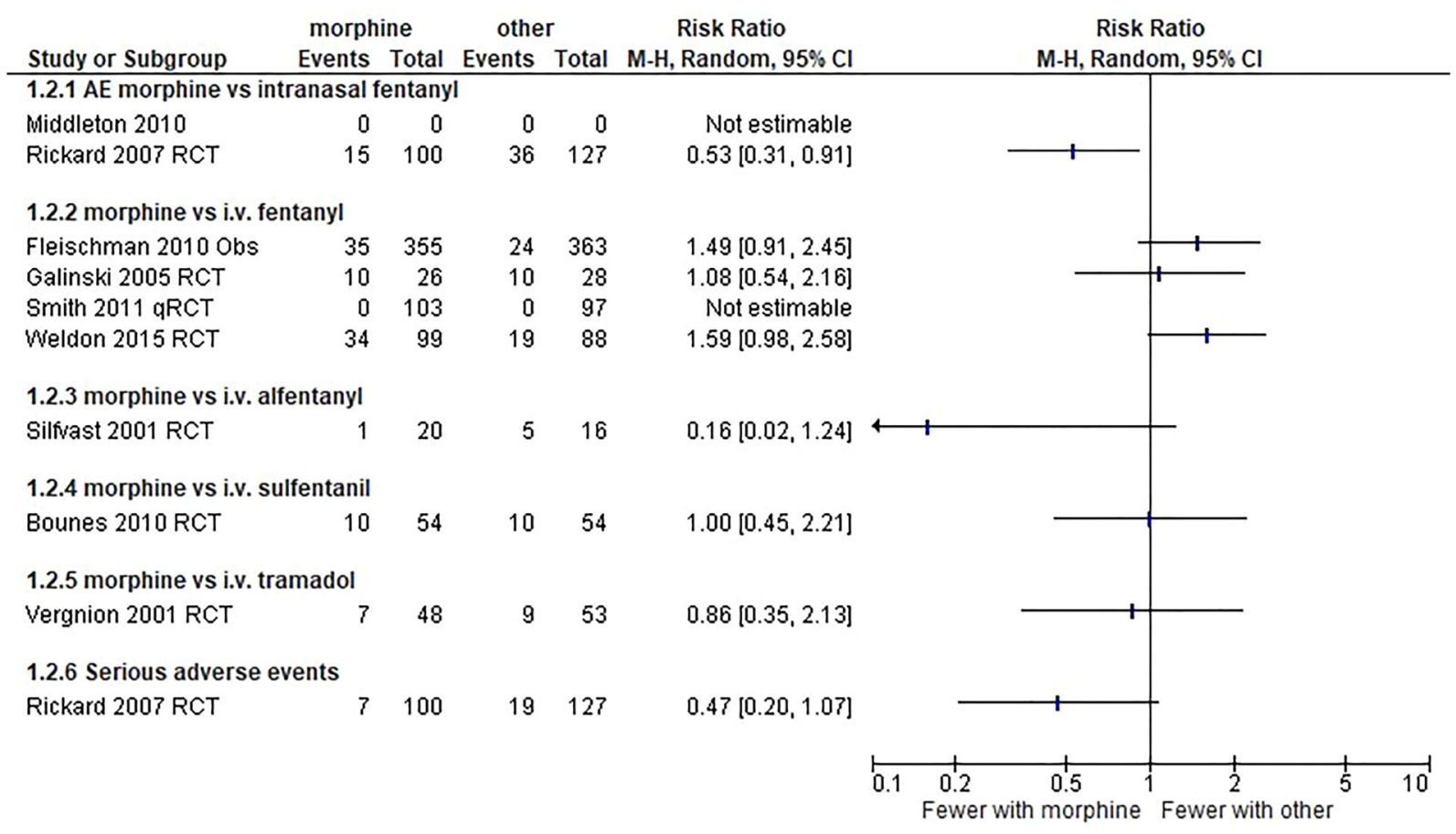

Fig. 4 Forest plot illustrating adverse events in patients treated with synthetic opioids vs. morphine. $R C T$ randomized controlled trial, $q R C T$ quasi-RCT, Obs observationalstudy, $A E$ standard adverse events, i.v. intravenous, $C I$ confidence interval, $v$ s versus 


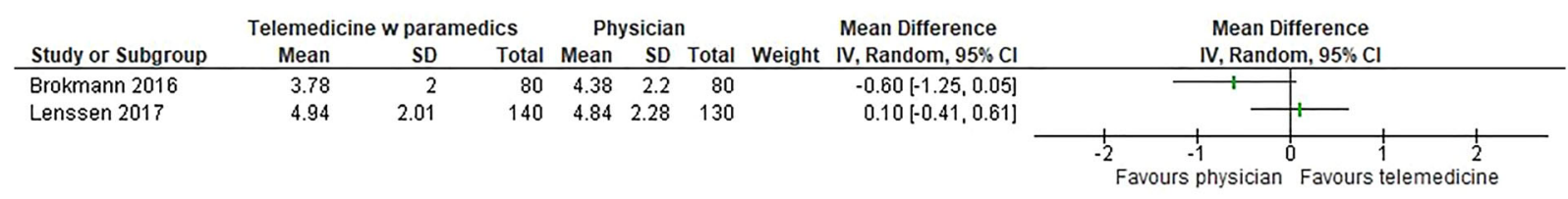

Fig. 5 Forest plot illustrating change in pain scores for patients treated by physicians versus paramedics. $S D$ standard deviation, i.v. intravenous, $C I$ confidence interval, vs versus

A French study $(n=108)$ on sufentanil, another fast-acting opioid, reported a similar analgesic effect of i.v sufentanil compared with i.v morphine (difference in proportion of patients with NRS $<4$ at $15 \mathrm{~min}: 4 \%$ [95\% CI - 13 to 21]). Results regarding vital signs and adverse effects (multiple; see Table 1) were nonconclusive (RR 1.00, 95\% CI 0.45-2.21) [28].

Fleischman et al. implemented paramedicadministered i.v. fentanyl and investigated the effect of this action in a diverse group of patients $(n=363)$. The authors found that pain (NRS) was reduced by 3.1 units (95\% CI 2.8-3.4) in the fentanyl group compared with 2.9 units (95\% CI 2.5-3.2) in the group receiving i.v. morphine $(n=355)$ before protocol change (difference between the groups: SMD - 0.06, $95 \%$ CI -0.21 to 0.09). The authors found similar reported numbers of adverse events (RR 1.49, 95\% CI 0.91-2.45), nausea, hypotension $(\mathrm{SBP}<90 \mathrm{mmHg}), \quad$ respiratory depression $(\mathrm{RR}<12 / \mathrm{min})$, hypoxemia $\left(\mathrm{SpO}_{2}<92 \%\right)$, and sedation (any decrease in GCS from baseline)) [35] in the two groups.

Finally, Vergnion et al. compared i.v. morphine with i.v. tramadol in 101 trauma patients. The groups were similar in terms of change in pain scores (VRS, 0-100: $-1.19 \pm 0.71$ [morphine] vs. $-1.21 \pm 0.70$ [tramadol]; difference: SMD $-0.03,95 \% \mathrm{CI}-0.42$ to 0.36 ), vital signs, and adverse events (nausea and vomiting) [27].

\section{Physicians Versus Non-physicians}

Two observational studies explored the possible effect of competency level of the attending clinician on the efficacy and safety of opioid administration (Table 2; Fig. 5). The overall quality of evidence was very low. Clinical heterogeneity prevented meta-analysis (statistical heterogeneity: $I^{2}=63$ ).

Lennssen et al. assessed the efficacy and safety of opioid therapy provided by paramedics compared with opioid therapy provided by prehospital physicians and found no difference in effect (change in NRS: $4.94 \pm 2.01$ and $4.84 \pm 2.28$, respectively; $P=0.5379$ ) or in the proportion of reported adverse events between the groups [36].

In a similar setup in Germany, Brokmann et al. found that analgesia was less effective in patients treated by telemedically-supported paramedics compared with patients treated by physicians (change in NRS: $3.78 \pm 2.0$ and $4.38 \pm 2.2, \quad$ respectively; $P=0.0159$ ). No adverse events were reported in either group [37].

\section{Opioids (i.v.) Versus Opioids Given by Another Route of Administration}

Two pre-hospital studies have explored the safety and/or efficacy of non-intravenous administration of opioids compared with i.v. opioid administration (Table 2; Figs. 3, 4). The overall quality of evidence was low for effect and very low for adverse events.

Rickard et al. randomized a miscellaneous patient group to receive either i.v. morphine $(n=100)$ or intranasal fentanyl $(n=127)$ and found similar analgesic effect (change in NRS: 3.57 [95\% CI $3.10-4.03]$ vs. 4.22 [95\% CI $3.71-4.71]$ ) in the two groups but reported a higher incidence of adverse events (see Table 1) in the group receiving intranasal fentanyl. Additionally, rescue analgesia was needed significantly earlier in patients given intranasal 
fentanyl compared with patients receiving i.v. morphine [33].

Middleton et al. found no difference in the change in pain scores (NRS: 4.5 [95\% CI 4.5-4.6] vs. 4.5 [95\% CI 4.4-4.6]) when comparing i.v. morphine with intranasal fentanyl in a large pre-hospital observational study. Adverse events were not reported [34].

\section{Opioids use in Frail Patients}

No pre-hospital studies assessed the risk of opioid administration in different groups of frail patients, such as geriatric patients, pregnant patients or patients with comorbidities.

\section{DISCUSSION}

In this systematic review investigating the prehospital administration of opioids for acute pain, both the number of relevant studies and the overall quality of evidence were low. The use of different pain scales (some not validated) by different author groups confuses evidence interpretation, hampers the possibility of metaanalysis, and confounds clear guidelines on prehospital pain management. Most previous reviews on the topic have been narrative $[5,14,3839]$, solely focused on trauma patients [19], or have increased the risk of indirectness by including the evidence based on emergency department (ED) studies [40, 41].

\section{Opioids Versus No Analgesia or Alternative Drugs}

We found no studies comparing the use of no analgesia or alternative, non-ketamine analgesic drugs with i.v. opioids in pre-hospital emergency care.

The published pre-hospital literature on opioids is characterized by being of low to very low quality based on single-arm feasibility studies reporting a reduction in pain during prehospital transport, a small number of side effects, and low occurrence of abnormal vital signs. From a clinical point of view, i.v. opioids are often needed to relieve severe acute pain, and they appear to be generally effective and safe when titrated cautiously to a monitored patient.

RCTs comparing opioids with placebo or weaker analgesics with a more beneficial safety profile cannot be conducted in an ethically safe way in the subset of patients with severe acute pain. For patients with mild or moderate pain, alternatives to opioids might be available and should be explored in future RCTs.

Recent pre-hospital studies have found an increased effect when combining ketamine with opioids, but also a higher incidence of adverse effects [42-44], compared with opioid-only therapy. The added analgesic effect of a combined therapy has been confirmed in an ED context [45], while a benefit of ketamine compared with morphine as monotherapy has not been demonstrated [46-48]. Inconclusive results appear when pooling the scarce evidence in a recent systematic review [22]. Other systemic analgesic adjuvants (e.g., midazolam and metoprolol) to i.v. morphine have been tested in the pre-hospital setting, but not proven to be effective $[49,50]$.

\section{Morphine (i.v.) Versus Synthetic Opioids (i.v.)}

We found moderate evidence that i.v. morphine and synthetic opioids are equally effective. There are uncertainties due to the few reported serious adverse events (low quality) or other adverse events (very low quality) both from i.v. morphine and synthetic opioids. Rapid analgesic onset may be a desirable feature of the newer synthetic opioids when applied in a prehospital setting. However, if not titrated sufficiently, the analgesic effect vanishes quickly, and for this reason morphine could be just as suitable in terms of relieving pain in the entire course of the pre-hospital patient care [51] as the synthetic alternatives.

\section{Physicians Versus Non-physicians}

Few studies have explored the possible impact of competency level of the pre-hospital healthcare provider on the efficacy and safety of opioid administration. The overall quality of 
evidence was very low, thus not allowing us to draw any conclusion. Intuitively, the quality of the pain management may be linked to the educational level of the clinicians.

We acknowledge that our distinction between physicians and non-physicians is a very crude way of addressing competency level as this may very well be more dependent on other factors, such as training and exposure, than on formal education [52, 53]. Therefore, we suggest that future focus should be on prioritizing repeated multifaceted educational efforts and continuous adjustments of pain management protocols in order to improve the quality of acute pain management [54-57].

\section{I.v. Opioids Versus Opioids Given by Another Route of Administration}

Low-quality evidence indicates a similar effect between i.v. morphine and intranasal fentanyl, but with a higher incidence of rescue analgesia and adverse events among patients receiving intranasal fentanyl. It may be worth noting that these studies compare groups of patients where both the agent and the route of administration differ between the groups. From a clinical point of view, analgesics with an easy administration profile may play a role in pre-hospital pain management, especially in cases where i.v. access is difficult or infeasible, such as in children or heavily obese patients.

\section{Opioids for Frail Patients}

We found no studies identifying groups of patients in whom pre-hospital opioid administration should be waived or carried out with extra caution. Theoretically, the risk of opioid accumulation increases with repeated administrations and larger cumulative doses affecting the duration of the analgesic effect as well as the occurrence of side-effects [58]. The magnitude and duration of analgesic effect is also highly individual and affected by numerous factors, such as age, comorbidity, obesity, frailty, and concomitant use of central nervous system depressants [7]. Potential side effects are numerous and should be recognized and handled promptly because some are potentially life-threatening $[7,10,59]$. Therefore, a cautious approach to frail patients seems sensible.

\section{Studies from Other Settings}

In a recent systematic review and meta-analysis by Sobieraj et al., the evidence for pre-hospital acute pain management was mainly based on ED studies [41]. These authors searched for alternatives to opioids and included 52 RCTs and 13 observational studies comparing the efficacy of opioids to that of ketamine, acetaminophen, nitrous oxide, and NSAIDs. They concluded that ketamine and opioids provided similar analgesia and that opioids seemed to have fewer side effects. The combined administration of ketamine and opioids seemed to relieve acute pain more than opioids as monotherapy [41].

Comparing opioids to acetaminophen or NSAIDs in these ED studies, Sobieraj et al. demonstrated no difference in reduction in pain scores [41]. Compared with patients given acetaminophen, more patients given opioids experienced dizziness whereas there was no difference in hypotension, sedation, or respiratory depression. It should be noted that patients included in ED pain studies may differ from those in pre-hospital studies in terms of initial pain status and clinical conditions and that the authors' exclusion of patients with severe pain may limit generalizability of findings to a broad spectrum of patients. Therefore, careful attention should be paid when extrapolating results from ED studies to the pre-hospital setting.

\section{CONCLUSION}

The evidence base for pre-hospital opioid administration to relieve acute pain is scarce and the overall quality of evidence low. The i.v. administration of synthetic, fast-acting opioids seems to be as effective and as safe as the i.v. administration of morphine. More controlled studies are needed to investigate alternative routes for opioid administration as well as prehospital pain management of potentially more frail patients. 


\section{ACKNOWLEDGEMENTS}

The authors would like to thank Research Librarian Jane Kjemtrup Andersen for developing the search strategy and conducting the searches for this review.

Funding. No funding or sponsorship was received for this study. The Rapid Service Fee was funded by the Scandinavian Society of Anaesthesia and Intensive care medicine (SSAI).

Authorship. All named authors meet the International Committee of Medical Journal Editors (ICMJE) criteria or authorship for this article, take responsibility for the integrity of the work as a whole, and have given their approval for this version to be published.

Author Contributions. KDF was the main author drafting the manuscript, reviewing all articles, and extracting data for further analyses. GEV extracted the data and carried out the statistical analyses, helped with data interpretation, and assisted in drafting the manuscript. PKH was the supervisor of the study design and coordination, helped with reviewing of articles and data extraction and interpretation, and assisted in the drafting of the manuscript. LR, JK, RL, PK, VM, MS, and MR were all contributors to the study design and coordination, helped with data interpretation, and assisted in drafting the manuscript. LR was the main supervisor of the study design and coordination, reviewed all articles, conducted data extraction, interpreted data, and assisted in the manuscript drafting. All authors participated in discussion and decision on the PICOs and the methodology of this systematic review. All authors contributed to and approved the protocol (CRD42018114399) as well as the final manuscript.

Disclosures. Kristian Dahl Friesgaard, Gunn Elisabeth Vist, Per Kristian Hyldmo, Lasse Raatiniemi, Jouni Kurola, Robert Larsen, Poul Kongstad, Vidar Magnusson, Mårten Sandberg, Marius Rehn, and Leif Rognås declare that they have no conflict of interest.
Compliance with Ethics Guidelines. This article is based on previously conducted studies and does not contain any new studies with human participants or animals performed by any of the authors.

Data Availability. The datasets used and/or analyzed during the current study are available from the corresponding author on reasonable request.

Open Access. This article is licensed under a Creative Commons Attribution-NonCommercial 4.0 International License, which permits any non-commercial use, sharing, adaptation, distribution and reproduction in any medium or format, as long as you give appropriate credit to the original author(s) and the source, provide a link to the Creative Commons licence, and indicate if changes were made. The images or other third party material in this article are included in the article's Creative Commons licence, unless indicated otherwise in a credit line to the material. If material is not included in the article's Creative Commons licence and your intended use is not permitted by statutory regulation or exceeds the permitted use, you will need to obtain permission directly from the copyright holder. To view a copy of this licence, visit http:// creativecommons.org/licenses/by-nc/4.0/.

\section{REFERENCES}

1. McLean SA, Maio RF, Domeier RM. The epidemiology of pain in the prehospital setting. Prehosp Emerg Care. 2002;6:402-5.

2. Jennings PA, Cameron P, Bernard S. Epidemiology of prehospital pain: an opportunity for improvement. Emerg Med J. 2011;28:530-1.

3. Galinski M, Ruscev M, Gonzalez G, et al. Prevalence and management of acute pain in prehospital emergency medicine. Prehosp Emerg Care. 2010;14: 334-9.

4. Friesgaard KD, Riddervold IS, Kirkegaard H, Christensen EF, Nikolajsen L. Acute pain in the prehospital setting: a register-based study of 41.241 
patients. Scand J Trauma Resusc Emerg Med. 2018;26:53.

5. McManus JG Jr, Sallee DR Jr. Pain management in the prehospital environment. Emerg Med Clin N Am. 2005;23:415-31.

6. Studnek JR, Fernandez AR, Vandeventer S, Davis S, Garvey L. The association between patients' perception of their overall quality of care and their perception of pain management in the prehospital setting. Prehosp Emerg Care. 2013;17:386-91.

7. Gropper MA, Miller RD, Eriksson LI, Fleisher LA, Wiener-Kronish JP, Cohen NH, Leslie K. Miller's Anesthesia, 2-Volume Set E-Book. Elsevier Health Sciences; 2019. https://www.eu.elsevierhealth.com/ millers-anesthesia-2-volume-set-9780323596046. html?gclid=EAIaIQobChMIrrns0eGG9QIVVvhRC h0VkgABEAQYASABEgJp7_D_BwE\&gclsrc=aw.ds.

8. Carr DB, Goudas LC. Acute pain. Lancet. 1999;353: 2051-8.

9. Upton RN, Semple TJ, Macintyre PE. Pharmacokinetic optimisation of opioid treatment in acute pain therapy. Clin Pharmacokinet. 1997;33:225-44.

10. Gupta K, Prasad A, Nagappa M, Wong J, Abrahamyan L, Chung F. Risk factors for opioid-induced respiratory depression and failure to rescue: a review. Curr Opin Anaesthesiol. 2018;31:110-9.

11. Han B, Compton WM, Blanco C, Crane E, Lee J, Jones CM. Prescription opioid use, misuse, and use disorders in U.S. adults: 2015 National survey on drug use and health. Ann Intern Med. 2017;167: 293-301.

12. Mounteney J, Giraudon I, Denissov G, Griffiths P. Fentanyls: are we missing the signs? Highly potent and on the rise in Europe. Int J Drug Policy. 2015;26:626-31.

13. Cousins MJ, Lynch ME. The Declaration Montreal: access to pain management is a fundamental human right. Pain. 2011;152:2673-4.

14. Alonso-Serra HM, Wesley K. Prehospital pain management. Prehosp Emerg Care. 2003;7:482-8.

15. Maio RF, Garrison HG, Spaite DW, et al. Emergency medical services outcomes project I (EMSOP I): prioritizing conditions for outcomes research. Ann Emerg Med. 1999;33:423-32.

16. Spaite DW, Maio R, Garrison HG, et al. Emergency Medical Services Outcomes Project (EMSOP) II: developing the foundation and conceptual models for out-of-hospital outcomes research. Ann Emerg Med. 2001;37:657-63.
17. Garrison HG, Maio RF, Spaite DW, et al. Emergency Medical Services Outcomes Project III (EMSOP III): the role of risk adjustment in out-of-hospital outcomes research. Ann Emerg Med. 2002;40:79-88.

18. Maio RF, Garrison HG, Spaite DW, et al. Emergency Medical Services Outcomes Project (EMSOP) IV: pain measurement in out-of-hospital outcomes research. Ann Emerg Med. 2002;40:172-9.

19. Gausche-Hill M, Brown KM, Oliver ZJ, et al. An evidence-based guideline for prehospital analgesia in trauma. Prehosp Emerg Care. 2014;18(Suppl 1): $25-34$.

20. Higgins JPT, Green S, editors. Cochrane handbook for systematic reviews of interventions. Chichester: Wiley; 2011.

21. Raatiniemi L, Magnusson V, Hyldmo PK, et al. Femoral nerve blocks for the treatment of acute prehospital pain: a systematic review with meta-analysis. Acta Anaesthesiol Scand. 2020;64:1038-47.

22. Sandberg M, Hyldmo PK, Kongstad P, et al. Ketamine for the treatment of prehospital acute pain: a systematic review of benefit and harm. BMJ Open. 2020;10:e038134.

23. The Scandinavian Society of Anaesthesiology and Intensive Care Medicine. Prehospital care: Scandinavian SSAI clinical practice guideline on prehospital pain management. 2020. https://www.ssai. info/guidelines/-preparation. Accessed 2 Feb 2021.

24. Veritas Health Innovation. Covidence systematic review software. 2019. http://www.covidence.org. Accessed 2 Feb 2021.

25. Balshem $H$, Helfand $M$, Schünemann $H J$, et al. GRADE guidelines: 3. Rating the quality of evidence. J Clin Epidemiol. 2011;64:401-6.

26. Smith MD, Wang Y, Cudnik M, Smith DA, Pakiela J, Emerman CL. The effectiveness and adverse events of morphine versus fentanyl on a physician-staffed helicopter. J Emerg Med. 2012;43:69-75.

27. Vergnion M, Degesves S, Garcet L, Magotteaux V. Tramadol, an alternative to morphine for treating posttraumatic pain in the prehospital situation. Anesth Analg. 2001;92:1543-6.

28. Bounes V, Barthelemy R, Diez O, Charpentier S, Montastruc JL, Ducasse JL. Sufentanil is not superior to morphine for the treatment of acute traumatic pain in an emergency setting: a randomized, double-blind, out-of-hospital trial. Ann Emerg Med. 2010;56:509-16.

29. Puymirat E, Lamhaut L, Bonnet N, et al. Correlates of pre-hospital morphine use in ST-elevation 
myocardial infarction patients and its association with in-hospital outcomes and long-term mortality: the FAST-MI (French Registry of Acute ST-elevation and non-ST-elevation Myocardial Infarction) programme. Eur Heart J. 2016;37:1063-71.

30. Weldon ER, Ariano RE, Grierson RA. Comparison of fentanyl and morphine in the prehospital treatment of ischemic type chest pain. Prehosp Emerg Care. 2016;20:45-51.

31. Silfvast T, Saarnivaara L. Comparison of alfentanil and morphine in the prehospital treatment of patients with acute ischaemic-type chest pain. Eur J Emerg Med. 2001;8:275-8.

32. Galinski M, Dolveck F, Borron SW, et al. A randomized, double-blind study comparing morphine with fentanyl in prehospital analgesia. Am J Emerg Med. 2005;23:114-9.

33. Rickard C, O'Meara P, McGrail M, Garner D, McLean A, Le Lievre P. A randomized controlled trial of intranasal fentanyl vs intravenous morphine for analgesia in the prehospital setting. Am J Emerg Med. 2007;25:911-7.

34. Middleton PM, Simpson PM, Sinclair G, Dobbins TA, Math B, Bendall JC. Effectiveness of morphine, fentanyl, and methoxyflurane in the prehospital setting. Prehosp Emerg Care. 2010;14:439-47.

35. Fleischman RJ, Frazer DG, Daya M, Jui J, Newgard CD. Effectiveness and safety of fentanyl compared with morphine for out-of-hospital analgesia. Prehosp Emerg Care. 2010;14:167-75.

36. Lenssen N, Krockauer A, Beckers SK, et al. Quality of analgesia in physician-operated telemedical prehospital emergency care is comparable to physician-based prehospital care-a retrospective longitudinal study. Sci Rep. 2017;7:1536.

37. Brokmann JC, Rossaint R, Hirsch F, et al. Analgesia by telemedically supported paramedics compared with physician-administered analgesia: a prospective, interventional, multicentre trial. Eur J Pain. 2016;20:1176-84.

38. Rupp $\mathrm{T}$, Delaney KA. Inadequate analgesia in emergency medicine. Ann Emerg Med. 2004;43: 494-503.

39. Yousefifard M, Askarian-Amiri S, Madani Neishaboori A, Sadeghi M, Saberian P, Baratloo A. Prehospital pain management; a systematic review of proposed guidelines. Arch Acad Emerg Med. 2019;7:e55.

40. Niemi-Murola L, Unkuri J, Hamunen K. Parenteral opioids in emergency medicine-a systematic review of efficacy and safety. Scand J Pain. 2011;2: 187-94.

41. Sobieraj DM, Martinez BK, Miao B, et al. Comparative effectiveness of analgesics to reduce acute pain in the prehospital setting. Prehosp Emerg Care. 2020;24:163-74.

42. Johansson P, Kongstad P, Johansson A. The effect of combined treatment with morphine sulphate and low-dose ketamine in a prehospital setting. Scand J Trauma Resusc Emerg Med. 2009;17:61.

43. Jennings PA, Cameron P, Bernard S, et al. Morphine and ketamine is superior to morphine alone for outof-hospital trauma analgesia: a randomized controlled trial. Ann Emerg Med. 2012;59:497-503.

44. Galinski M, Dolveck F, Combes X, et al. Management of severe acute pain in emergency settings: ketamine reduces morphine consumption. Am J Emerg Med. 2007;25:385-90.

45. Beaudoin FL, Lin C, Guan W, Merchant RC. Lowdose ketamine improves pain relief in patients receiving intravenous opioids for acute pain in the emergency department: results of a randomized, double-blind, clinical trial. Acad Emerg Med. 2014;21:1193-202.

46. Miller JP, Schauer SG, Ganem VJ, Bebarta VS. Lowdose ketamine vs morphine for acute pain in the ED: a randomized controlled trial. Am J Emerg Med. 2015;33:402-8.

47. Motov S, Rockoff $\mathrm{B}$, Cohen $\mathrm{V}$, et al. Intravenous subdissociative-dose ketamine versus morphine for Analgesia in the Emergency Department: a randomized controlled trial. Ann Emerg Med. 2015;66: 222-9.

48. Tran KP, Nguyen Q, Truong XN, et al. A comparison of ketamine and morphine analgesia in prehospital trauma care: a cluster randomized clinical trial in rural Quang Tri province. Vietnam Prehosp Emerg Care. 2014;18:257-64.

49. Auffret Y, Gouillou M, Jacob GR, et al. Does midazolam enhance pain control in prehospital management of traumatic severe pain? Am J Emerg Med. 2014;32:655-9.

50. Zedigh C, Alho A, Hammar E, et al. Aspects on the intensity and the relief of pain in the prehospital phase of acute coronary syndrome: experiences from a randomized clinical trial. Coron Artery Dis. 2010;21:113-20.

51. Aubrun F, Mazoit JX, Riou B. Postoperative intravenous morphine titration. Br J Anaesth. 2012;108: 193-201. 
52. Walsh B, Cone DC, Meyer EM, Larkin GL. Paramedic attitudes regarding prehospital analgesia. Prehosp Emerg Care. 2013;17:78-87.

53. Berben SA, Meijs TH, van Grunsven PM, Schoonhoven L, van Achterberg T. Facilitators and barriers in pain management for trauma patients in the chain of emergency care. Injury. 2012;43:1397-402.

54. Ricard-Hibon A, Chollet C, Saada S, Loridant B, Marty J. A quality control program for acute pain management in out-of-hospital critical care medicine. Ann Emerg Med. 1999;34:738-44.

55. Brown KM, Hirshon JM, Alcorta R, et al. The implementation and evaluation of an evidencebased statewide prehospital pain management protocol developed using the national prehospital evidence-based guideline model process for emergency medical services. Prehosp Emerg Care. 2014;18(Suppl 1):45-51.
56. French SC, Salama NP, Baqai S, Raslavicus S, Ramaker J, Chan SB. Effects of an educational intervention on prehospital pain management. Prehosp Emerg Care. 2006;10:71-6.

57. French SC, Chan SB, Ramaker J. Education on prehospital pain management: a follow-up study. West J Emerg Med. 2013;14:96-102.

58. Peng PW, Sandler AN. A review of the use of fentanyl analgesia in the management of acute pain in adults. Anesthesiology. 1999;90:576-99.

59. Zhang Z, Xu F, Zhang C, Liang X. Activation of opioid $\mathrm{mu}$ receptors in caudal medullary raphe region inhibits the ventilatory response to hypercapnia in anesthetized rats. Anesthesiology. 2007;107:288-97. 